\title{
Comparison of outcomes between muscle-sparing thoracotomy and video-assisted thoracic surgery in patients with cT1 NO M0 lung cancer
}

\author{
Yue Zhao, MD, ${ }^{\mathrm{a}, \mathrm{b}}$ Guodong Li, MD, ${ }^{\mathrm{b}, \mathrm{c}}$ Yang Zhang, MD, ${ }^{\mathrm{a}, \mathrm{b}}$ Hong Hu, MD, ${ }^{\mathrm{a}, \mathrm{b}}$ Jie Zhang, MD, \\ Yihua Sun, MD, a,b and Haiquan Chen, MD ${ }^{\mathrm{a}, \mathrm{b}}$
}

\section{ABSTRACT}

Objective: To compare short-term complications and long-term survival outcomes between muscle-sparing thoracotomy (MST) and video-assisted thoracic surgery (VATS) groups using a propensity-score matching process.

Methods: One thousand eighty-three patients with cT1 N0 M0 lung cancer from January 2009 to December 2014 who underwent lobectomy and a systematic lymph node dissection were retrospectively included, and statistical analyses including a propensity-score matching process were used to compare shortterm and long-term outcomes.

Results: Before propensity-score matching, for short-term surgical outcomes, the VATS group had fewer chest tube dwelling days $(P<.001)$, less chest tube output $(P<.001)$, shorter hospital stay, and fewer postoperative complications $(P=.015)$. For long-term survival outcomes, the VATS group had a longer recurrence-free survival $(P<.001)$ and overall survival $(P<.001)$. After propensity-score matching, for short-term surgical outcomes, the VATS group had fewer chest tube dwelling days $(P<.001)$, less chest tube output $(P<.001)$, shorter hospital stay $(P=.002)$, and fewer postoperative complications $(P=.008)$. There was no difference in recurrence-free survival and overall survival between the 2 groups ( $P=.158$ and $P=.639$, respectively).

Conclusions: VATS is less invasive and is associated with shorter length of hospital stay and fewer postoperative complications. The 2 surgical approaches have equivalent long-term survival outcomes. (J Thorac Cardiovasc Surg 2017;154:1420-1429)

Lung cancer is among the most frequently diagnosed cancers worldwide, with the highest mortality rate among men and the second highest mortality rate

\footnotetext{
From the Departments of ${ }^{\text {a}}$ Thoracic Surgery and ${ }^{\mathrm{c}}$ Intervention Therapy, Fudan University Shanghai Cancer Center; and ${ }^{\mathrm{b}}$ Department of Oncology, Shanghai Medical College, Fudan University, Shanghai, China.

Supported by the National Natural Science Foundation of China (grant Nos. $81330056,81401886,81401891,81422029,81472173$, and 81372525) and the Key Project of Science and Technology Commission of Shanghai Municipality (grant No. JGGG1302).

Y.Z., G.L., Drs Y.Z., and H.H. contributed equally to this article.

Received for publication Sept 1, 2016; revisions received April 2, 2017; accepted for publication April 22, 2017; available ahead of print June 23, 2017

Address for reprints: Haiquan Chen, MD, Department of Thoracic Surgery, Fudan University Shanghai Cancer Center, 270 Dong-An Rd, Shanghai 200032, China (E-mail: hqchen1@yahoo.com).

0022-5223/\$36.00

Copyright (c) 2017 by The American Association for Thoracic Surgery

http://dx.doi.org/10.1016/j.jtcvs.2017.04.071
}

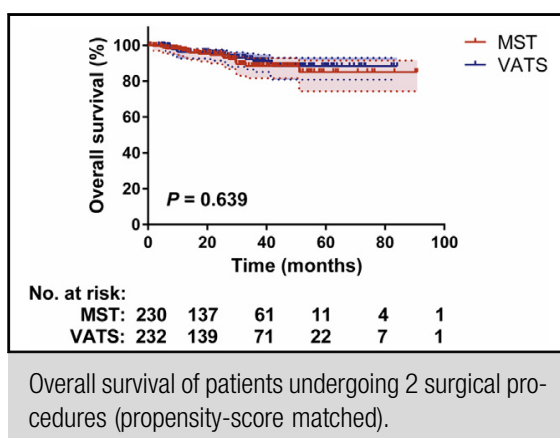

\section{Central Message}

Compared with muscle-sparing thoracotomy, video-assisted thoracic surgery has fewer postoperative complications, whereas their longterm survival outcomes are equivalent.

\section{Perspective}

Our study uses propensity-score matching process to balance preoperative covariates, and demonstrates that compared with musclesparing thoracotomy, video-assisted thoracic surgery results in fewer postoperative complications, although their long-term survival outcomes are equivalent.

See Editorial Commentary page 1430. among women. ${ }^{1}$ Lobectomy and a systematic lymph node dissection can be performed using videoassisted thoracic surgery (VATS) or muscle-sparing thoracotomy (MST) as a minimally invasive surgical procedure.

Several studies have reported that compared with open thoracotomy, VATS had lower rates of postoperative complications and a shorter hospital stay in patients with early stage lung cancer. ${ }^{2-8}$ In addition, several studies have

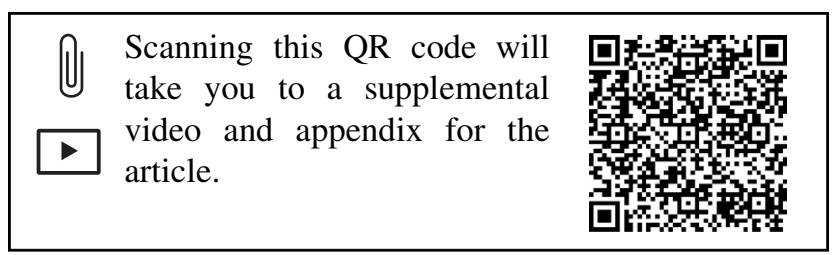




$$
\begin{aligned}
& \text { Abbreviations and Acronyms } \\
& \begin{aligned}
\mathrm{BMI}= & \text { body mass index } \\
\mathrm{CT} & =\text { computed tomography } \\
\mathrm{FEV} 1 \%= & \text { percent of forced expiratory volume in } \\
& 1 \text { second predicted } \\
\mathrm{MST}= & \text { muscle-sparing thoracotomy } \\
\mathrm{MVV} \%= & \text { percent of maximum voluntary } \\
& \text { ventilation predicted } \\
\text { OS }=\text { overall survival } & \text { RFS }=\text { recurrence-free survival } \\
\text { VATS }= & \text { video-assisted thoracic surgery }
\end{aligned}
\end{aligned}
$$

reported that both VATS and open thoracotomy had equivalent long-term survival outcomes. ${ }^{7,9}$ However, only a few studies in the literature focused on the comparison of short-term postoperative complications and long-term survival outcomes between VATS and MST. Thus, this question still needs further clarifying and more evidence focusing on this topic is needed. ${ }^{10}$

We retrospectively reviewed 1083 patients with cT1 N0 M0 lung cancer from January 2009 to December 2014 from Fudan University Shanghai Cancer Center to compare the short-term postoperative outcomes and long-term survival outcomes between VATS and MST lobectomy. A propensity-score matching process was used to balance significant preoperative covariates and minimize potential biases.

\section{PATIENTS AND METHODS \\ Patients}

One thousand eighty-three patients with cT1 N0 M0 lung cancer during the period January 2009 to December 2014 treated at Fudan University Shanghai Cancer Center who had MST or VATS lobectomy were retrospectively included in this study. Patients who had a previous history of malignancy, underwent a neoadjuvant therapy, or had stage IV disease were excluded (Figure 1). To determine the clinical stage before surgery, patients received enhanced chest computed tomography (CT) scanning and positron emission tomography-CT scanning. Those patients who did not receive positron emission tomography-CT scanning received an enhanced brain CT or magnetic resonance imaging, whole-body bone scanning, and abdominal CT or ultrasonography. Fiber optic bronchoscopy was routinely performed. Patients were grouped into the MST group or VATS group according to the surgical procedure they underwent. Informed consents of included patients were waived because this was a retrospective study. This study was approved by the Committee for Ethical Review of Research (Fudan University Shanghai Cancer Center Institutional Review Board No. 090977-1).

\section{Surgical Approaches}

Both MST and VATS were performed under general anesthesia and single-lung ventilation using a double-lumen endobronchial tube. Patients were placed in a lateral decubitus position. The MST procedure was started with a posterolateral 7- to $13-\mathrm{cm}$ long skin incision at the fourth or fifth intercostal space. The latissimus dorsi was exposed and retracted posteriorly and the serratus anterior muscle was split along its muscle fibers. The VATS procedure was performed using a 3-port technique. The observation port was placed initially at the sixth or seventh intercostal space on the middle axillary line. The utility port was placed at the seventh or eighth

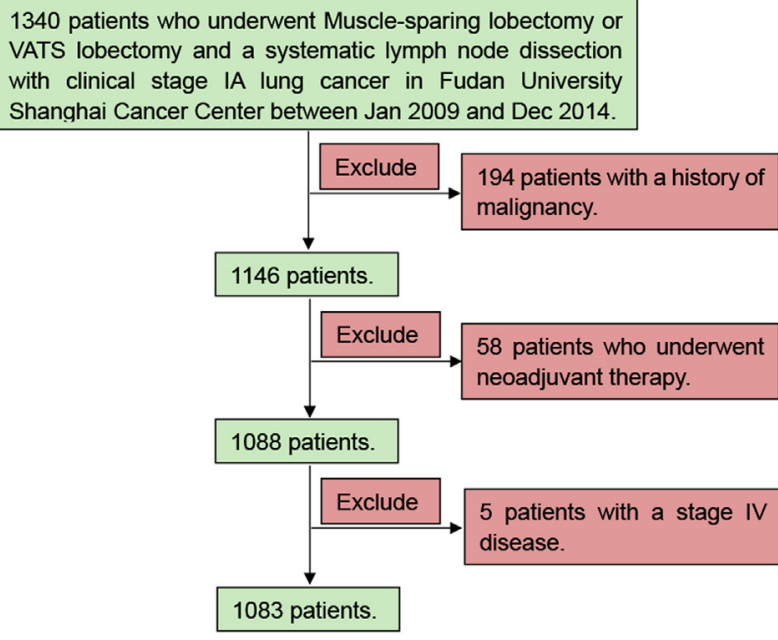

FIGURE 1. Patient selection and exclusion criteria. VATS, Video-assisted thoracic surgery.

intercostal space on the posterior axillary line. And an additional 5- to 7-cm incision was made along the fourth intercostal space for taking out the resected lobe. Lobectomy and a systematic mediastinal lymph node dissection were performed in both MST and VATS groups. The systematic lymph node dissection was performed according to the tumor location. Lymph node stations 7, 8, 10, and 11 were routinely dissected regardless of the tumor location. Additionally, for a tumor located in the left upper lobe, lymph node stations 4,5 , and 6 were routinely dissected. For a tumor located in the left lower lobe, lymph node stations 4, 5, 6, and 9 were routinely dissected. For a tumor located in the right upper lobe, lymph node stations 2 and 4 were routinely dissected, and station 3 was optionally dissected. For a tumor located in the right middle lobe, lymph node stations 2 and 4 were routinely dissected, and station 3 was optionally dissected. For a tumor located in the right lower lobe, lymph node stations 2, 4, and 9 were routinely dissected, and station 3 was optionally dissected (Video 1). Resected tumors and lymph nodes were reviewed by pathologists to determine the pathologic stage, according to the current seventh edition of the TNM staging system of lung cancer. ${ }^{11}$ Regional lymph node stations were defined as Mountain and Dresler described in $1997 .^{12}$

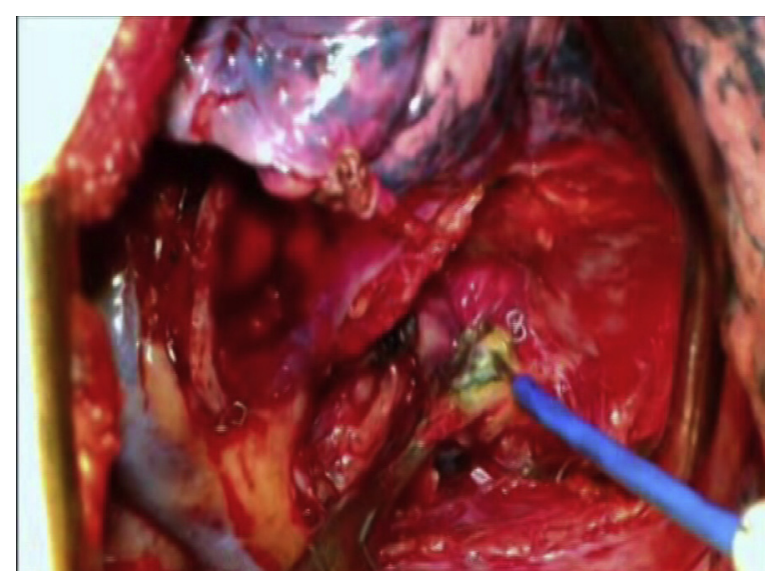

VIDEO 1. Open right upper lobectomy subcarinal lymph node dissection. Video available at: http://www.jtcvsonline.org/article/S0022-5223(17) 31049-8/addons. 
TABLE 1. Baseline clinical characteristics before matching $(N=1083)$

\begin{tabular}{|c|c|c|c|c|}
\hline & $\begin{array}{c}\text { Muscle-sparing } \\
\text { thoracotomy }(n=\mathbf{5 6 0})\end{array}$ & $\begin{array}{c}\text { Video-associated } \\
\text { thoracic surgery }(n=523)\end{array}$ & $P$ value & $\begin{array}{c}\text { Standardized } \\
\text { mean difference }\end{array}$ \\
\hline Gender & & & $<.001$ & 0.281 \\
\hline Male & $320(57.1)$ & $226(43.2)$ & & \\
\hline Female & $240(42.9)$ & $297(56.8)$ & & \\
\hline Age & $61.3 \pm 10.1$ & $59.2 \pm 9.2$ & .001 & 0.212 \\
\hline BMI & $23.3 \pm 3.0$ & $23.4 \pm 2.9$ & 620 & 0.030 \\
\hline Smoking status & & & $<.001$ & 0.329 \\
\hline Former/current & $223(39.8)$ & $129(24.7)$ & & \\
\hline Never & $337(60.2)$ & $394(75.3)$ & & \\
\hline FEV1\% & $87.2 \pm 16.5$ & $91.3 \pm 15.9$ & $<.001$ & 0.254 \\
\hline MVV\% & $82.7 \pm 24.3$ & $84.7 \pm 23.6$ & .187 & 0.080 \\
\hline Tumor location & & & .937 & 0.055 \\
\hline LUL & $152(27.1)$ & $144(27.5)$ & & \\
\hline LLL & $82(14.6)$ & $85(16.3)$ & & \\
\hline RUL & $177(31.6)$ & $155(29.6)$ & & \\
\hline RML & $48(8.6)$ & $45(8.6)$ & & \\
\hline RLL & $101(18.0)$ & $94(18.0)$ & & \\
\hline Central/peripheral & & & $<.001$ & 0.285 \\
\hline Central & $39(7.0)$ & $7(1.3)$ & & \\
\hline Peripheral & $521(93.0)$ & $516(98.7)$ & & \\
\hline $\begin{array}{l}\text { Tumor size on chest computed } \\
\text { tomography scan, } \mathrm{cm}\end{array}$ & $2.2 \pm 0.6$ & $1.8 \pm 0.7$ & $<.001$ & 0.648 \\
\hline Clinical T stage & & & $<.001$ & 0.522 \\
\hline $1 \mathrm{a}$ & $236(42.1)$ & $352(67.3)$ & & \\
\hline $1 \mathrm{~b}$ & $324(57.9)$ & $171(32.7)$ & & \\
\hline Preoperative comorbidities & $145(25.9)$ & $148(28.3)$ & .373 & 0.054 \\
\hline $\begin{array}{c}\text { Number of preoperative } \\
\text { comorbidities }\end{array}$ & & & .867 & 0.068 \\
\hline 0 & $415(74.1)$ & $375(71.7)$ & & \\
\hline 1 & $115(20.5)$ & $116(22.2)$ & & \\
\hline 2 & $25(4.5)$ & $25(4.8)$ & & \\
\hline 3 & $3(0.5)$ & $5(1.0)$ & & \\
\hline 4 & $2(0.4)$ & $2(0.4)$ & & \\
\hline Chronic bronchitis & $13(2.3)$ & $4(0.8)$ & .039 & 0.127 \\
\hline Emphysema & $1(0.2)$ & $3(0.6)$ & .358 & 0.065 \\
\hline Asthma & $3(0.5)$ & $3(0.6)$ & 1.000 & 0.005 \\
\hline Bronchiectasis & $3(0.5)$ & $3(0.6)$ & 1.000 & 0.005 \\
\hline Tuberculosis & $8(1.4)$ & $11(2.1)$ & .398 & 0.051 \\
\hline Pneumonia & $2(0.4)$ & $1(0.2)$ & 1.000 & 0.032 \\
\hline Coronary artery disease & $9(1.6)$ & $13(2.5)$ & .306 & 0.062 \\
\hline Hypertension & $100(17.9)$ & $108(20.7)$ & .244 & 0.071 \\
\hline Diabetes mellitus & $28(5.0)$ & $25(4.8)$ & .867 & 0.010 \\
\hline
\end{tabular}

Values are presented as $\mathrm{n}(\%)$ or mean \pm standard deviation. $B M I$, Body mass index; $F E V I \%$, percent of forced expiratory volume in 1 second predicted; $M V V \%$, percent of maximum voluntary ventilation predicted; $L U L$, left upper lobe; $L L L$, left lower lobe; $R U L$, right upper lobe; $R M L$, right middle lobe; $R L L$, right lower lobe.

\section{Follow-up Protocol}

Patient follow-up was a part of our routine clinical practice and started the day he or she received surgery. The start point was considered the day he or she received surgery. After surgery, patients came to the hospital to undergo a routine examination, including chest $\mathrm{CT}$, brain MRI, and abdominal ultrasonography every 3 months for the first 2 years after surgery, every 6 months for the next 2 years after surgery, and once a year from then on. A telephone follow-up would be made if the patient did not come to the clinic. The follow-up work started during January 2009 and ended during June 2016. Overall survival (OS) was considered the 
TABLE 2. Surgical outcomes and postoperative complications before matching $(\mathbf{N}=\mathbf{1 0 8 3})$

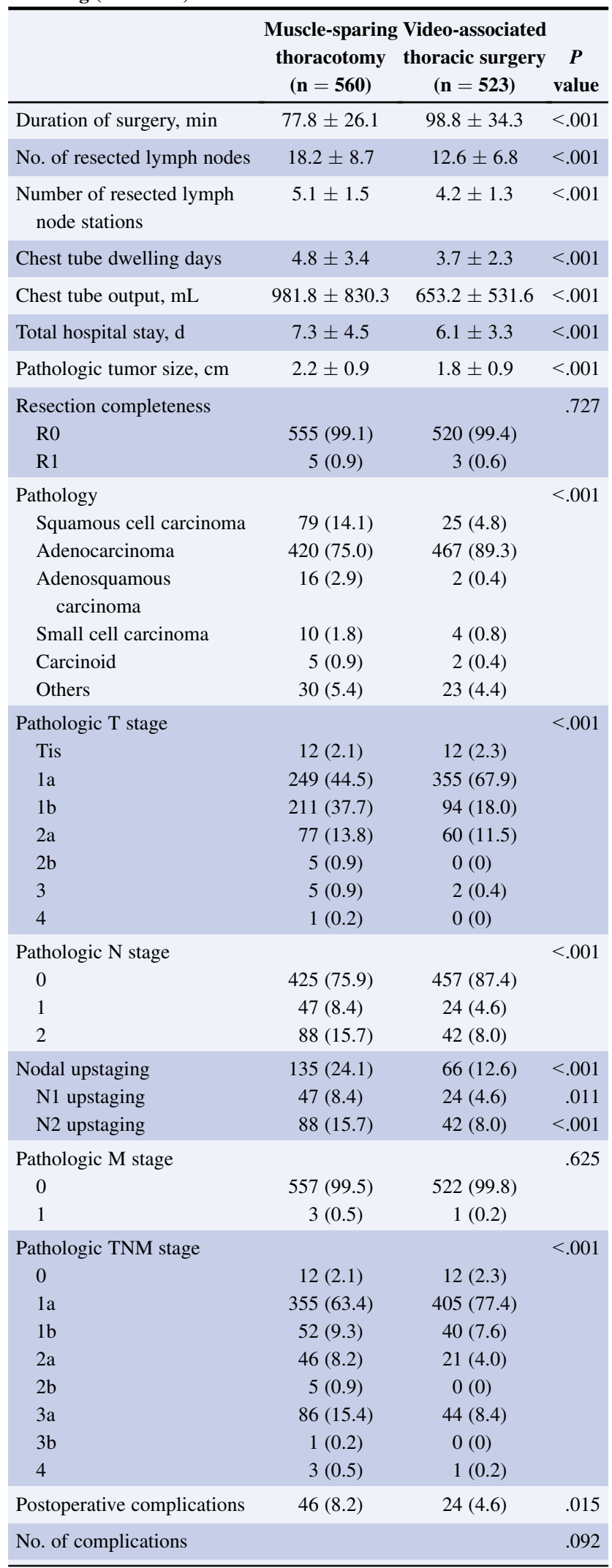

(Continued)
TABLE 2. Continued

\begin{tabular}{lccc}
\hline & $\begin{array}{c}\text { Muscle-sparing Video-associated } \\
\text { thoracotomy } \\
\text { thoracic surgery }\end{array}$ & $\begin{array}{c}\boldsymbol{P} \\
(\mathbf{n}=\mathbf{5 6 0})\end{array}$ & $\begin{array}{c}\text { 523) } \\
\text { value }\end{array}$ \\
\hline 0 & $514(91.8)$ & $499(95.4)$ & \\
1 & $37(6.6)$ & $21(4.0)$ & \\
2 & $6(1.1)$ & $2(0.4)$ & \\
3 & $3(0.5)$ & $1(0.2)$ & \\
\hline Massive hemorrhage & $3(0.5)$ & $1(0.2)$ & .625 \\
Chylothorax & $14(2.5)$ & $2(0.4)$ & .004 \\
\hline Bronchopleural fistula & $0(0)$ & $1(0.2)$ & .483 \\
Alveolopleural fistula & $20(3.6)$ & $15(2.9)$ & .513 \\
\hline Pneumonia & $7(1.3)$ & $4(0.8)$ & .426 \\
\hline Atelectasis & $4(0.7)$ & $2(0.4)$ & .688 \\
\hline Arrhythmia & $4(0.7)$ & $2(0.4)$ & .688 \\
Respiratory failure & $5(0.9)$ & $0(0)$ & .063 \\
\hline Reoperation & $1(0.2)$ & $1(0.2)$ & 1.000 \\
Postoperative death & $1(0.2)$ & $0(0)$ & 1.000 \\
\hline
\end{tabular}

Values are presented as $\mathrm{n}(\%)$ or mean \pm standard deviation.

time between the day of surgery and the day of death from any cause. Patients with no event were censored at the date of their last follow-up. Recurrence-free survival (RFS) was considered the time between the day of surgery and the day of disease recurrence. Patients who died before disease recurrence were censored on the date of their last alive follow-up, and patients with no event were censored on the date of their last follow-up.

\section{Propensity-score Matching}

To adjust for significant preoperative covariates between the 2 groups, a propensity-score matching process using a logistic regression model was used to reduce potential biases. Patient baseline clinical characteristics, including gender; age; body mass index (BMI); smoking status; percent of forced expiratory volume in 1 second predicted (FEV1\%); percent of maximum voluntary ventilation predicted (MVV\%); tumor location; central or peripheral location on chest CT scan; tumor size on chest CT scan; and preoperative comorbidities, including chronic bronchitis, emphysema, asthma, bronchiectasis, tuberculosis, pneumonia, coronary artery disease, hypertension, and diabetes mellitus were considered as covariates for propensity-score matching. The propensity-score matching process was performed using the nearest method, with the number of patients of each group being 1:1. Caliper was set 0.005 . Baseline standardized mean differences were calculated before and after propensity-score matching.

\section{Statistical Analyses}

Patients' clinical and pathologic characteristics before and after propensity-score matching, including gender, age, BMI, smoking status, FEV1\%, MVV\%, tumor location, central or peripheral location on chest CT scan, tumor size on chest CT scan, clinical T stage, preoperative comorbidities, duration of surgery, number of resected lymph nodes, number of resected lymph node stations, chest tube dwelling days, chest tube output, total hospital stay, pathologic tumor size, resection completeness, pathology, pathologic stage, and postoperative complications were recorded. Student $t$ test was used to compare continuous variables between the MST and VATS groups, whereas Pearson $\chi^{2}$ test and Fisher exact test were used to compare categorical variables wherever applicable. Kaplan-Meier survival curves for both groups were used to depict the RFS and OS before and after 
TABLE 3. Baseline clinical characteristics after matching $(n=482)$

\begin{tabular}{|c|c|c|c|c|}
\hline & $\begin{array}{c}\text { Muscle-sparing } \\
\text { thoracotomy }(n=241)\end{array}$ & $\begin{array}{c}\text { Video-associated } \\
\text { thoracic surgery }(n=241)\end{array}$ & $P$ value & $\begin{array}{c}\text { Standardized } \\
\text { mean difference }\end{array}$ \\
\hline Gender & & & .855 & 0.017 \\
\hline Male & $124(51.5)$ & $126(52.3)$ & & \\
\hline Female & $117(48.5)$ & $115(47.7)$ & & \\
\hline Age, y & $60.9 \pm 10.5$ & $60.7 \pm 9.3$ & .799 & 0.023 \\
\hline BMI & $23.5 \pm 3.0$ & $23.3 \pm 2.8$ & .601 & 0.048 \\
\hline Smoking status & & & .920 & 0.009 \\
\hline Former/current & 69 (28.6) & $68(28.2)$ & & \\
\hline Never & $172(71.4)$ & $173(71.8)$ & & \\
\hline FEV1\% & $89.0 \pm 16.1$ & $88.9 \pm 15.9$ & .898 & 0.012 \\
\hline MVV\% & $82.9 \pm 22.9$ & $84.0 \pm 23.6$ & .605 & 0.047 \\
\hline Tumor location & & & .809 & 0.115 \\
\hline LUL & $73(30.3)$ & $62(25.7)$ & & \\
\hline LLL & $35(14.5)$ & $42(17.4)$ & & \\
\hline RUL & $70(29.0)$ & $72(29.9)$ & & \\
\hline RML & $20(8.3)$ & $21(8.7)$ & & \\
\hline RLL & $43(17.8)$ & $44(18.3)$ & & \\
\hline Central/peripheral & & & .760 & 0.028 \\
\hline Central & $6(2.5)$ & $5(2.1)$ & & \\
\hline Peripheral & $235(97.5)$ & $236(97.9)$ & & \\
\hline $\begin{array}{l}\text { Tumor size on chest computed } \\
\text { tomography scan, } \mathrm{cm}\end{array}$ & $2.0 \pm 0.6$ & $2.1 \pm 0.6$ & .928 & 0.008 \\
\hline Clinical T stage & & & 1.000 & $<0.001$ \\
\hline $1 \mathrm{a}$ & $127(52.7)$ & $127(52.7)$ & & \\
\hline $1 \mathrm{~b}$ & $114(47.3)$ & $114(47.3)$ & & \\
\hline Preoperative comorbidities & $70(29.0)$ & $70(29.0)$ & 1.000 & $<0.001$ \\
\hline $\begin{array}{l}\text { No. of preoperative } \\
\text { comorbidities }\end{array}$ & & & .891 & 0.097 \\
\hline 0 & $171(71.0)$ & $171(71.0)$ & & \\
\hline 1 & $53(22.0)$ & $56(23.2)$ & & \\
\hline 2 & $13(5.4)$ & $12(5.0)$ & & \\
\hline 3 & $3(1.2)$ & $1(0.4)$ & & \\
\hline 4 & $1(0.4)$ & $1(0.4)$ & & \\
\hline Chronic bronchitis & $5(2.1)$ & $2(0.8)$ & .450 & 0.104 \\
\hline Emphysema & $1(0.4)$ & $0(0)$ & 1.000 & 0.091 \\
\hline Asthma & $2(0.8)$ & $2(0.8)$ & 1.000 & $<0.001$ \\
\hline Bronchiectasis & $1(0.4)$ & $3(1.2)$ & .623 & 0.092 \\
\hline Tuberculosis & $5(2.1)$ & $4(1.7)$ & 1.000 & 0.031 \\
\hline Pneumonia & $1(0.4)$ & $1(0.4)$ & 1.000 & $<0.001$ \\
\hline Coronary artery disease & $7(2.9)$ & $5(2.1)$ & .559 & 0.053 \\
\hline Hypertension & $49(20.3)$ & $50(20.7)$ & .910 & 0.010 \\
\hline Diabetes mellitus & $14(5.8)$ & $13(5.4)$ & .843 & 0.018 \\
\hline
\end{tabular}

Values are presented as $\mathrm{n}(\%)$ or mean \pm standard deviation. $B M I$, Body mass index; $F E V I \%$, percent of forced expiratory volume in 1 second predicted; $M V V \%$, percent of maximum voluntary ventilation predicted; $L U L$, left upper lobe; $L L L$, left lower lobe; $R U L$, right upper lobe; $R M L$, right middle lobe; $R L L$, right lower lobe.

propensity-score matching, and log-rank test was used to compare the survival outcomes of the 2 groups. Patients who died before discharge were excluded from the survival analysis. Moreover, to identify whether the surgical approach was the independent prognostic factor, multivariable analyses for overall survival using Cox regression model adjusting for patient gender, age, BMI, smoking status, FEV1\%, MVV\%, tumor location, central or peripheral location on chest CT scan, tumor size on chest CT scan, and preoperative complication, along with the surgical approach, 


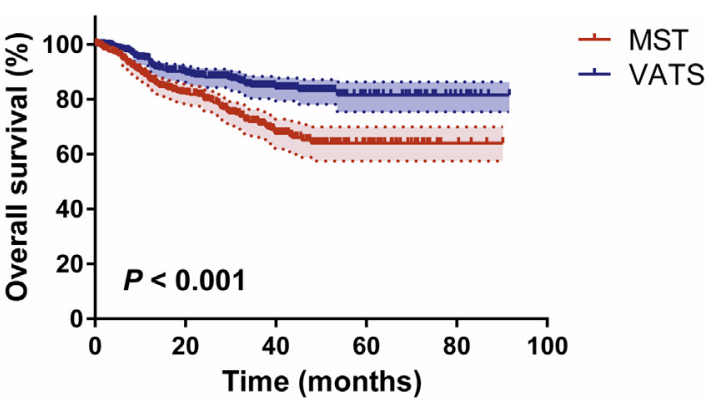

No. at risk:

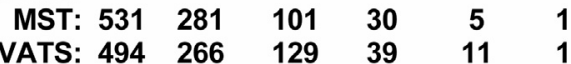

FIGURE 2. Recurrence-free survival of unmatched patients in the muscle-sparing thoracotomy group (MST) and video-assisted thoracic surgery (VATS) group.

were performed both before and after propensity-score matching. All statistical analyses were performed using SPSS (version 22.0, IBMSPSS Inc, Armonk, NY) and R (version 3.3.0, R Foundation for Statistical Computing, Vienna, Austria). Survival curves were depicted using GraphPad Prism (version 6.01, GraphPad Software Inc, La Jolla, Calif).

\section{RESULTS}

Before propensity-score matching, 560 of the 1083 patients were in the MST group, and 523 were in the VATS group. Their baseline clinical characteristics before propensity-score matching ae shown in Table 1. There were significant differences in patient gender $(P<.001)$, age $(P=.001)$, smoking status $(P<.001)$, central or peripheral location on chest CT scan $(P<.001)$, tumor size on chest $\mathrm{CT}$ scan $(P<.001)$, clinical T stage $(P<.001)$, and preoperative chronic bronchitis between the MST and VATS groups (Table 1). For short-term surgical outcomes, compared with patients in the MST group, patients in the VATS group had more surgical time $(98.8 \pm 34.3$ vs $77.8 \pm 26.1 ; P<.001)$, fewer lymph nodes resected $(12.6 \pm 6.8$ vs $18.2 \pm 8.7 ; P<.001)$, fewer lymph node

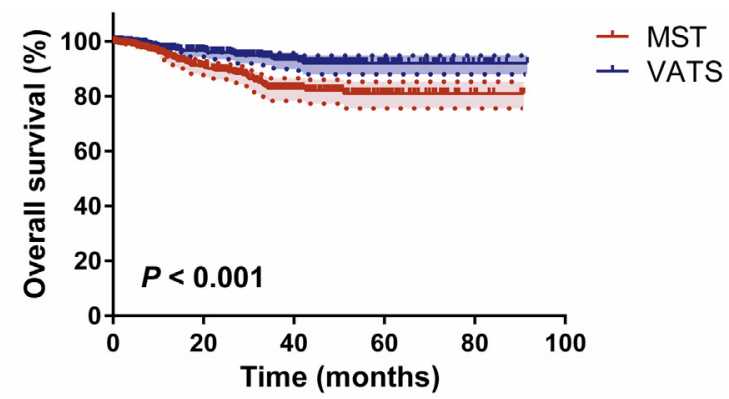

No. at risk:

$\begin{array}{rrrrrr}\text { MST: } 531 & 318 & 134 & 38 & 6 & 1 \\ \text { VATS: } 494 & 291 & 149 & 46 & 16 & 1\end{array}$

FIGURE 3. Overall survival of unmatched patients in the muscle-sparing thoracotomy (MST) group and video-assisted thoracic surgery (VATS) group.

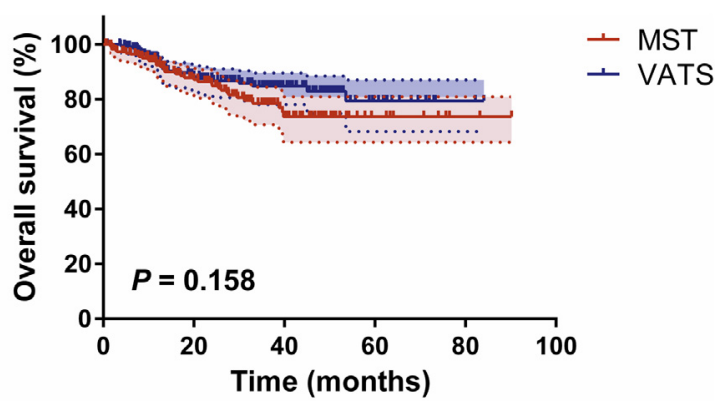

No. at risk:

MST: $230 \quad 123 \quad 134 \quad 45 \quad 10 \quad 1$

VATS: $232 \quad 125 \quad 149 \quad 61 \quad 18 \quad 1$

FIGURE 4. Recurrence-free survival of matched patients in the musclesparing thoracotomy (MST) group and video-assisted thoracic surgery (VATS) group.

stations resected $(4.2 \pm 1.3$ vs $5.1 \pm 1.5 ; P<.001)$, fewer chest tube dwelling days $(3.7 \pm 2.3$ vs $4.8 \pm 3.4$; $P<.001)$, less chest tube output, $(653.2 \pm 531.6$ vs $981.8 \pm 830.3 ; P<.001)$, fewer days of hospital stay $(6.1 \pm 3.3$ vs $7.3 \pm 4.5 ; P<.001)$, and a pathologically confirmed smaller tumor size $(1.8 \pm 0.9$ vs $2.2 \pm 0.9$; $P<.001$ ). In addition, the comparison of pathologic types between the 2 groups were significantly different $(P<.001)$. More patients in the MST group had squamous cell carcinoma ( $14.1 \%$ vs $4.8 \%)$, whereas more patients in the VATS group had adenocarcinoma $(75.0 \%$ vs $89.3 \%)$. Moreover, we compared the pathologic stage of patients between both groups. In general, patients in the MST group had higher pathologically confirmed T, N, and TNM stages, as shown in Table 2. Additionally, nodal upstaging was more frequently seen in the MST group $(24.1 \%$ vs $12.6 \% ; P<.001)$. Finally, we compared the postoperative complications between these 2 groups, and results showed that patients in the VATS group had fewer postoperative complications than patients in the MST group (4.6\% vs $8.2 \% ; P=.015)$. For each individual complication, our

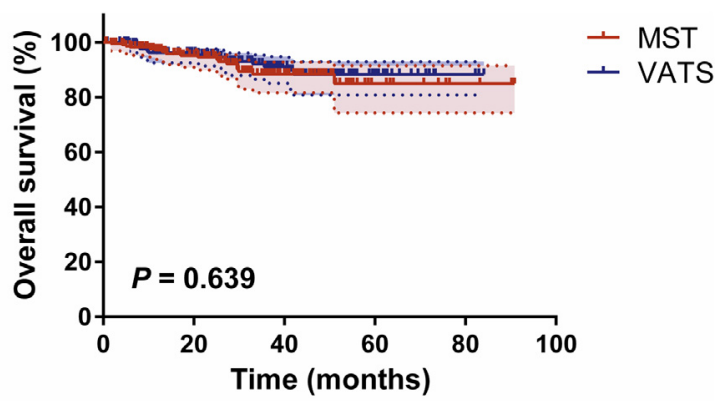

No. at risk:

$\begin{array}{llllll}\text { MST: } 230 & 137 & 61 & 11 & 4 & 1 \\ \text { VATS: } 232 & 139 & 71 & 22 & 7 & 1\end{array}$

FIGURE 5. Overall survival of matched patients in the muscle-sparing thoracotomy (MST) group and video-assisted thoracic surgery (VATS) group. 
data showed that there was a higher rate of chylothorax in the MST group $(2.5 \%$ vs $0.4 \% ; P=.004)$ (Table 2$)$.

After propensity-score matching, there were 482 patients, with 241 patients in either group. And there were no significant differences in compared baseline clinical characteristics, as shown in Table 3. The distribution of propensity scores across 2 groups was demonstrated in Figure E1. For short-term surgical outcomes, compared with patients in the MST group, patients in the VATS group had more surgical time $(98.8 \pm 34.5$ vs $78.0 \pm 26.0$; $P<.001)$, fewer lymph nodes resected $(12.6 \pm 6.9$ vs $17.9 \pm 8.1 ; P<.001)$, fewer lymph node stations resected ( $4.3 \pm 1.4$ vs $5.1 \pm 1.6 ; P<.001)$, fewer chest tube dwelling days $(3.7 \pm 2.3$ vs $4.8 \pm 3.7 ; P<.001)$, less chest tube output $(672.2 \pm 564.9$ vs $942.6 \pm 781.3, P<.001)$, and fewer days of hospital stay $(6.0 \pm 3.6$ vs $7.1 \pm 3.8$; $P=.002)$. There were no significant differences in pathologically confirmed tumor size; pathologic type; nodal upstaging; and pathologically confirmed $\mathrm{T}, \mathrm{N}$, and TNM stages. However, there was still a significant difference of postoperative complications between these 2 groups $(9.1 \%$ vs $3.3 \% ; P=.008)$, and a higher rate of chylothorax for the MST group $(2.5 \%$ vs $0 \% ; P=.030)$.

To compare the long-term survival outcomes between the MST and VATS groups, we performed survival analyses using Kaplan-Meier survival curves and log-rank tests. The median follow-up time was 29.0 months for all patients and 29.1 months for matched patients. In an unadjusted comparison, VATS showed superior recurrence-free survival $(P<.001)$ and overall survival $(P<.001)$; however after adjusting for patient factors (eg, gender and age), there was no difference $(P=.152$ for RFS and $P=.639$ for OS) (Figures 2-5).

To see whether surgical approach was an independent prognostic factor, we performed a multivariable analysis for overall survival using Cox regression hazards model before and after propensity-score matching. The Cox regression hazards model was adjusted for patient gender, age, BMI, smoking status, FEV1\%, MVV\%, tumor location, central or peripheral location on chest CT scan, tumor size, preoperative complications, and surgical approach. In the unmatched analysis, age, tumor size on chest CT scan, and surgical approach were shown to be independent prognostic factors for patients' OS (Table 4), whereas in the matched analysis, age, tumor size on chest CT scan, and whether there was a preoperative complication were shown to be independent prognostic factors for patients' OS (Table 5).

\section{DISCUSSION}

Minimally invasive approaches are widely used in patients with early stage lung cancer. VATS has been shown to be a feasible minimally invasive surgical approach and associated with short hospital stay, lower rates of postoperative
TABLE 4. Multivariable analysis for overall survival in unmatched groups using Cox regression hazards model

\begin{tabular}{|c|c|c|c|}
\hline & $\begin{array}{c}\text { Hazard } \\
\text { ratio }\end{array}$ & $\begin{array}{c}95 \% \text { Confidence } \\
\text { interval } \\
\end{array}$ & $P$ value \\
\hline \multicolumn{4}{|l|}{ Sex } \\
\hline Female & Reference & - & - \\
\hline Male & 0.879 & $0.454-1.701$ & .701 \\
\hline Age (continuous) & 1.044 & $1.018-1.072$ & .001 \\
\hline BMI (continuous) & 0.950 & $0.883-1.022$ & 166 \\
\hline \multicolumn{4}{|l|}{ Smoking status } \\
\hline Never & Reference & - & - \\
\hline Former/current & 1.672 & $0.901-3.104$ & .103 \\
\hline FEV1\% (continuous) & 1.004 & $0.989-1.018$ & .607 \\
\hline MVV\% (continuous) & 0.999 & $0.987-1.010$ & .802 \\
\hline \multicolumn{4}{|l|}{ Tumor location } \\
\hline Right upper lobe & Reference & - & - \\
\hline Right middle lobe & 0.758 & $0.410-1.403$ & .378 \\
\hline Right lower lobe & 0.690 & $0.251-1.896$ & .472 \\
\hline Left upper lobe & 0.808 & $0.395-1.653$ & .560 \\
\hline Left lower lobe & 0.815 & $0.438-1.514$ & .517 \\
\hline \multicolumn{4}{|l|}{ Central/peripheral } \\
\hline Central & Reference & - & - \\
\hline Peripheral & 0.652 & $0.306-1.390$ & .268 \\
\hline $\begin{array}{l}\text { Tumor size (computed } \\
\text { tomography, continuous) }\end{array}$ & 2.309 & $1.565-3.405$ & $<.001$ \\
\hline \multicolumn{4}{|l|}{ Preoperative complication } \\
\hline No & Reference & - & - \\
\hline Yes & 1.368 & $0.867-2.157$ & .178 \\
\hline \multicolumn{4}{|l|}{ Surgical approach } \\
\hline MST & Reference & - & - \\
\hline VATS & 0.581 & $0.354-0.954$ & .032 \\
\hline
\end{tabular}

$B M I$, Body mass index; $F E V 1 \%$, percent of forced expiratory volume in 1 second predicted; $M V V \%$, percent of maximum voluntary ventilation predicted; $M S T$, musclesparing thoracotomy; VATS, video-assisted thoracic surgery.

complications, and less pain by a number of studies in the past 2 decades. ${ }^{2-8,13-16}$ Several studies also reported that VATS and open thoracotomy had equivalent long-term survival outcomes. ${ }^{4,7,17}$ There was also a randomized controlled trial ${ }^{18}$ for lymph node dissection (American College of Surgeons Oncology Group Z0030), which also made a secondary analysis comparing long-term surgical outcome between open lobectomy and VATS using propensity-score matching. In their comparison between 686 patients in the open thoracotomy group and 66 patients in the VATS group, both disease-free survival and overall survival showed no significant difference. However, the number of studies focusing on the comparison between VATS and the less invasive muscle-sparing thoracotomy in the literature is limited. Kuritzky and colleagues ${ }^{19}$ conducted a propensity-score matched analysis and found that compared with MST lobectomy, VATS lobectomy for clinical stage I non-small cell lung cancer had similar short-term and long-term outcomes. 
TABLE 5. Multivariable analysis for overall survival in matched groups using Cox regression hazards model

\begin{tabular}{|c|c|c|c|}
\hline & $\begin{array}{c}\text { Hazard } \\
\text { ratio }\end{array}$ & $\begin{array}{c}95 \% \text { Confidence } \\
\text { interval } \\
\end{array}$ & $P$ value \\
\hline \multicolumn{4}{|l|}{ Sex } \\
\hline Female & Reference & - & - \\
\hline Male & 0.535 & $0.186-1.540$ & .246 \\
\hline Age (continuous) & 1.045 & $1.000-1.092$ & .050 \\
\hline BMI (continuous) & 0.921 & $0.814-1.042$ & .191 \\
\hline \multicolumn{4}{|l|}{ Smoking status } \\
\hline Never & Reference & - & - \\
\hline Former/current & 2.204 & $0.749-6.487$ & .151 \\
\hline FEV1\% (continuous) & 0.990 & $0.964-1.015$ & .424 \\
\hline MVV\% (continuous) & 1.008 & $0.988-1.028$ & .460 \\
\hline \multicolumn{4}{|l|}{ Tumor location } \\
\hline Right upper lobe & Reference & - & - \\
\hline Right middle lobe & 0.785 & $0.267-2.309$ & .660 \\
\hline Right lower lobe & 1.568 & $0.417-5.891$ & .506 \\
\hline Left upper lobe & 1.132 & $0.350-3.656$ & .836 \\
\hline Left lower lobe & 0.759 & $0.264-2.182$ & .609 \\
\hline \multicolumn{4}{|l|}{ Central/peripheral } \\
\hline Central & Reference & - & - \\
\hline Peripheral & 0.338 & $0.073-1.560$ & .165 \\
\hline $\begin{array}{l}\text { Tumor size (computed } \\
\text { tomography, continuous) }\end{array}$ & 3.522 & $1.798-6.898$ & $<.001$ \\
\hline \multicolumn{4}{|l|}{ Preoperative complication } \\
\hline No & Reference & - & - \\
\hline Yes & 2.077 & $1.002-4.305$ & .049 \\
\hline \multicolumn{4}{|l|}{ Surgical approach } \\
\hline MST & Reference & - & - \\
\hline VATS & 0.837 & $0.416-1.685$ & .619 \\
\hline
\end{tabular}

BMI, Body mass index; $F E V I \%$, percent of forced expiratory volume in 1 second predicted; $M V V \%$, percent of maximum voluntary ventilation predicted; $M S T$, musclesparing thoracotomy; VATS, video-assisted thoracic surgery.

More data are needed to have this issue better understood. Based on this background, we conducted this propensityscore matched, nonrandomized, retrospective study.

There were several propensity-score matched studies focusing on the topic of nodal upstaging in the literature. Medbery and colleagues ${ }^{20}$ demonstrated that nodal upstaging was more common after open thoracotomy than after VATS. However, in an academic or research facility, there was no difference between the 2 groups. Moreover, Boffa and colleagues ${ }^{21}$ found that upstaging from N0 to N1 was more common in the open thoracotomy group, whereas upstaging from $\mathrm{N} 0$ to $\mathrm{N} 2$ was similar in the 2 groups. Our results demonstrate that before propensity-score matching, nodal upstaging was more commonly seen in the MST group than in the VATS group. However, after propensity-score matching, there was no longer a significant difference (Tables 2 and 6). These results suggested that the differences were due to tumor and patient characteristics, rather than the technique in patients with a cT1 N0 M0 lung cancer.
TABLE 6. Surgical outcomes and postoperative complications after matching $(n=482)$

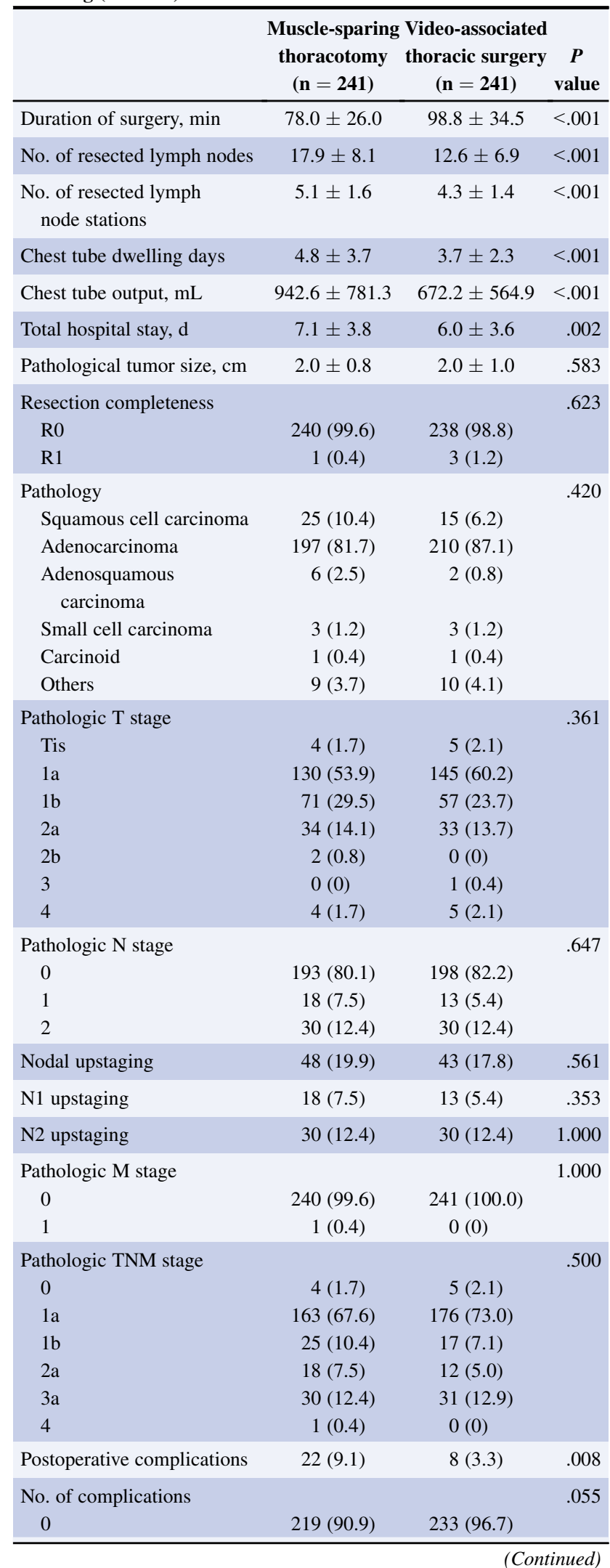


TABLE 6. Continued

\begin{tabular}{lccc}
\hline & $\begin{array}{c}\text { Muscle-sparing Video-associated } \\
\text { thoracotomy } \\
(\mathbf{n}=\mathbf{2 4 1})\end{array}$ & $\begin{array}{c}\text { thoracic surgery } \\
(\mathbf{n}=\mathbf{2 4 1})\end{array}$ & $\begin{array}{c}\boldsymbol{P} \\
\text { value }\end{array}$ \\
\hline 1 & $17(7.1)$ & $7(2.9)$ & \\
2 & $3(1.2)$ & $1(0.4)$ & \\
3 & $2(0.8)$ & $0(0)$ & \\
\hline Massive hemorrhage & $2(0.8)$ & $1(0.4)$ & 1.000 \\
Chylothorax & $6(2.5)$ & $0(0)$ & .030 \\
Bronchopleural fistula & $0(0)$ & $0(0)$ & - \\
Alveolopleural fistula & $9(3.7)$ & $4(1.7)$ & .160 \\
\hline Pneumonia & $4(1.7)$ & $2(0.8)$ & .686 \\
Atelectasis & $3(1.2)$ & $0(0)$ & .248 \\
\hline Arrhythmia & $2(0.8)$ & $1(0.4)$ & 1.000 \\
Respiratory failure & $3(1.2)$ & $0(0)$ & .248 \\
\hline Reoperation & $0(0)$ & $1(0.4)$ & 1.000 \\
\hline Postoperative death & $0(0)$ & $0(0)$ & - \\
\hline
\end{tabular}

Values are presented as mean \pm standard deviation or $\mathrm{n}(\%)$.

In our study, we found that compared with the minimally invasive MST lobectomy, VATS lobectomy was associated with shorter hospital stay, fewer chest tube dwelling days, less chest tube output, and fewer postoperative complications both before and after the propensity-score matching process, which were consistent with several previous studies. ${ }^{2-8,13-16}$ Moreover, the number of resected lymph nodes and lymph node stations were fewer for VATS lobectomy, which might correlate with the lower rate of postoperative chylothorax (Tables 2 and 6). Additionally, our study found that after adjusting for the preoperative covariates, although the number of resected lymph nodes and lymph node stations of VATS group were fewer, there was no significant difference of nodal upstaging status between the 2 surgical groups. This interesting finding suggests that when controlled for other preoperative confounders, MST lobectomy itself does not show a significant superiority on assessing nodal status over VATS lobectomy in patients with early stage lung cancer, although more lymph nodes and lymph node stations were resected using the MST approach. This leads to another question that is still unclear: How many lymph nodes resected is enough ${ }^{22,23}$ Intuitively, the more lymph nodes resected, the lower false negative rate should we get. But our study shows that different surgical approaches result in different lymph nodes resected, but their long-term RFS and OS were equivalent. Although this topic is beyond the objective of this article, this interesting finding is still worth mentioning.

For long-term survival outcomes, our results demonstrated that in an unadjusted comparison, VATS showed superior RFS and OS; however, after adjusting for patient factors (eg, gender and age), there was no significant difference. These results suggest VATS and MST lobectomy have equivalent long-term survival outcomes, which is consistent with several studies discussing the comparison between VATS and open thoracotomy. ${ }^{4,7,17}$ These findings showed that it was the tumor and patients' characteristics that drove the differences in RFS and OS, rather than the surgical approach itself. Moreover, as shown in Table 5, surgical approach was not an independent prognostic factor for patients' OS. Instead, tumor size on CT scan, patients' age, and whether a patient had preoperative complications were shown to be independent prognostic factors for patients' OS.

The unique advantage of our study is that we have a large number of patients. With the help of this large population, we were able to perform statistical analyses in enough patients after discarding hundreds of them in the propensity-score matching process, even if we narrowed the caliper to 0.005 , to make our study cohort very homogeneous. The analysis of this large number of patients gives us a straightforward, precise, and reliable conclusion.

There are also limitations. The propensity-score matching process using a logistic regression model was reported to be effective to adjust for significant confounders and reduce potential biases in retrospective studies; however, unlike randomized controlled trials, it has the limitation that it does not reduce the biases caused by unobserved covariates. ${ }^{24,25}$ In our daily practice, we tend not to perform VATS on those patients with worse disease (eg, patients with a bigger tumor on the chest CT scan or patients who smoke). In our experience, patients in the MST group had more exudates and pleural adhesion and the number of lymph nodes they had per se was greater than that of their counterparts in the VATS group. Some lymph node stations dissected were pathologically confirmed as inflammatory lesions that were not counted as a dissected lymph node station, and this phenomenon more commonly occurred when we performed VATS procedures. Undoubtedly, the best evidence should come from a large, randomized controlled trial. A retrospective study using propensity-score matching should never be considered as the substitute for a prospective study. Another issue that was not discussed in our article is alternative approaches of open thoracotomy, such as retracting the latissimus dorsi anteriorly without splitting the serratus anterior muscle, and rib shingling. Compared with these 2 approaches, retracting the latissimus dorsi posteriorly with the serratus anterior muscle split along its muscle fibers, as described in this article, has the advantage of a smaller incision, less bleeding, and shorter recovery time. The issue of the comparison between VATS lobectomy and minimally invasive MST lobectomy still needs more 
evidence to be better understood. Thus, we hope more studies, especially large, randomized prospective studies focusing on this topic will come out in the future, to better improve this field and benefit more patients.

\section{Conflict of Interest Statement}

Authors have nothing to disclose with regard to commercial support.

\section{References}

1. Torre LA, Bray F, Siegel RL, Ferlay J, Lortet-Tieulent J, Jemal A. Global cancer statistics, 2012. CA Cancer J Clin. 2015;65:87-108.

2. Boffa DJ, Dhamija A, Kosinski AS, Kim AW, Detterbeck FC, Mitchell JD, et al. Fewer complications result from a video-assisted approach to anatomic resection of clinical stage I lung cancer. J Thorac Cardiovasc Surg. 2014;148:637-43.

3. Smith CB, Kale M, Mhango G, Neugut AI, Hershman DL, Mandeli JP, et al. Comparative outcomes of elderly stage I lung cancer patients treated with segmentectomy via video-assisted thoracoscopic surgery versus open resection. $J$ Thorac Oncol. 2014;9:383-9.

4. Yang HX, Woo KM, Sima CS, Bains MS, Adusumilli PS, Huang J, et al. Longterm survival based on the surgical approach to lobectomy for clinical stage i nonsmall cell lung cancer: comparison of robotic, video-assisted thoracic surgery, and thoracotomy lobectomy. Ann Surg. 2017;265:431-7.

5. Scott WJ, Matteotti RS, Egleston BL, Oseni S, Flaherty JF. A comparison of perioperative outcomes of video-assisted thoracic surgical (VATS) lobectomy with open thoracotomy and lobectomy: results of an analysis using propensity score based weighting. Ann Surg Innov Res. 2010;4:1.

6. Falcoz PE, Puyraveau M, Thomas PA, Decaluwe H, Hürtgen M, Petersen RH. Video-assisted thoracoscopic surgery versus open lobectomy for primary nonsmall-cell lung cancer: a propensity-matched analysis of outcome from the European Society of Thoracic Surgeon database. Eur J Cardiothorac Surg. 2016; 49:602-9.

7. Murakawa T, Ichinose J, Hino H, Kitano K, Konoeda C, Nakajima J. Long-term outcomes of open and video-assisted thoracoscopic lung lobectomy for the treatment of early stage non-small cell lung cancer are similar: a propensity-matched study. World J Surg. 2015;39:1084-91.

8. Cao C, Manganas C, Ang SC, Peeceeyen S, Yan TD. Video-assisted thoracic surgery versus open thoracotomy for non-small cell lung cancer: a meta-analysis of propensity score-matched patients. Interact Cardiovasc Thorac Surg. 2013;16: 244-9.

9. Cao C, Zhu ZH, Yan TD, Wang Q, Jiang G, Liu L, et al. Video-assisted thoracic surgery versus open thoracotomy for non-small-cell lung cancer: a propensity score analysis based on a multi-institutional registry. Eur J Cardiothorac Surg. 2013;44:849-54.

10. Kuritzky AM, Ng T. Video-assisted thoracic surgery vs muscle-sparing thoracotomy: prioritizing randomized trial to assess complications and long-term survival over cost comparisons: In reply to Spartalis and colleagues. J Am Coll Surg. 2015; 221:890-1.

11. Goldstraw P, Crowley J, Chansky K, Giroux DJ, Groome PA, Rami-Porta R, et al. The IASLC Lung Cancer Staging Project: proposals for the revision of the TNM stage groupings in the forthcoming (seventh) edition of the TNM Classification of malignant tumours. J Thorac Oncol. 2007;2:706-14.

12. Mountain CF, Dresler CM. Regional lymph node classification for lung cancer staging. Chest. 1997;111:1718-23.

13. Yim AP, Wan S, Lee TW, Arifi AA. VATS lobectomy reduces cytokine responses compared with conventional surgery. Ann Thorac Surg. 2000;70: 243-7.

14. Nicastri DG, Wisnivesky JP, Litle VR, Yun J, Chin C, Dembitzer FR, et al. Thoracoscopic lobectomy: report on safety, discharge independence, pain, and chemotherapy tolerance. J Thorac Cardiovasc Surg. 2008;135:642-7.

15. Paul S, Sedrakyan A, Chiu YL, Nasar A, Port JL, Lee PC, et al. Outcomes after lobectomy using thoracoscopy vs thoracotomy: a comparative effectiveness analysis utilizing the Nationwide Inpatient Sample database. Eur J Cardiothorac Surg. 2013;43:813-7.

16. Bendixen M, Jorgensen OD, Kronborg C, Andersen C, Licht PB. Postoperative pain and quality of life after lobectomy via video-assisted thoracoscopic surgery or anterolateral thoracotomy for early stage lung cancer: a randomised controlled trial. Lancet Oncol. 2016;17:836-44.

17. Yang CF, Meyerhoff RR, Mayne NR, Singhapricha T, Toomey CB, Speicher PJ, et al. Long-term survival following open versus thoracoscopic lobectomy after preoperative chemotherapy for non-small cell lung cancer. Eur J Cardiothorac Surg. 2016;49:1615-23.

18. Su S, Scoot WJ, Allen MS, Darling GE, Decker PA, McKenna RJ, et al. Pattern of survival and recurrence after surgical treatment of early stage non-small cell lung carcinoma in the ACOSOG Z0030 (ALLIANCE) trial. J Thorac Cardiovasc Surg. 2014;147:747-52.

19. Kuritzky AM, Aswad BI, Jones RN, Ng T. Lobectomy by video-assisted thoracic surgery vs muscle-sparing thoracotomy for stage I lung cancer: a critical evaluation of short- and long-term outcomes. J Am Coll Surg. 2015;220:1044-53.

20. Medbery RL, Gillespie TW, Liu Y, Nickleach DC, Lipscomb J, Sancheti MS, et al. Nodal upstaging is more common with thoracotomy than with vats during lobectomy for early-stage lung cancer: an analysis from the National Cancer Data Base. J Thorac Oncol. 2016;11:222-33.

21. Boffa DJ, Kosinski AS, Paul S, Mitchell JD, Onaitis M. Lymph node evaluation by open or video-assisted approaches in 11,500 anatomic lung cancer resections. Ann Thorac Surg. 2012;94:347-53.

22. Darling GE, Allen MS, Decker PA, Ballman K, Malthaner RA, Inculet RI et al. Number of lymph nodes harvested from a mediastinal lymphadenectomy: results of the randomized, prospective American College of Surgeons Oncology Group Z0030 trial. Chest. 2011;139:1124-9.

23. David EA, Cooke DT, Chen Y, Nijar K, Canter RJ, Cress RD. Does lymph node count influence survival in surgically resected non-small cell lung cancer? Ann Thorac Surg. 2017;103:226-35.

24. D'Agostino RB Jr. Propensity score methods for bias reduction in the comparison of a treatment to a non-randomized control group. Stat Med. 1998; 17:2265-81.

25. Pages PB, Delpy JP, Orsini B, Gossot D, Baste JM, Thomas P, et al. Propensity score analysis comparing videothoracoscopic lobectomy with thoracotomy: A French nationwide study. Ann Thorac Surg. 2016;101:1370-8.

Key Words: muscle-sparing thoracotomy, video-assisted thoracic surgery, lung cancer 


\section{Distribution of Propensity Scores}
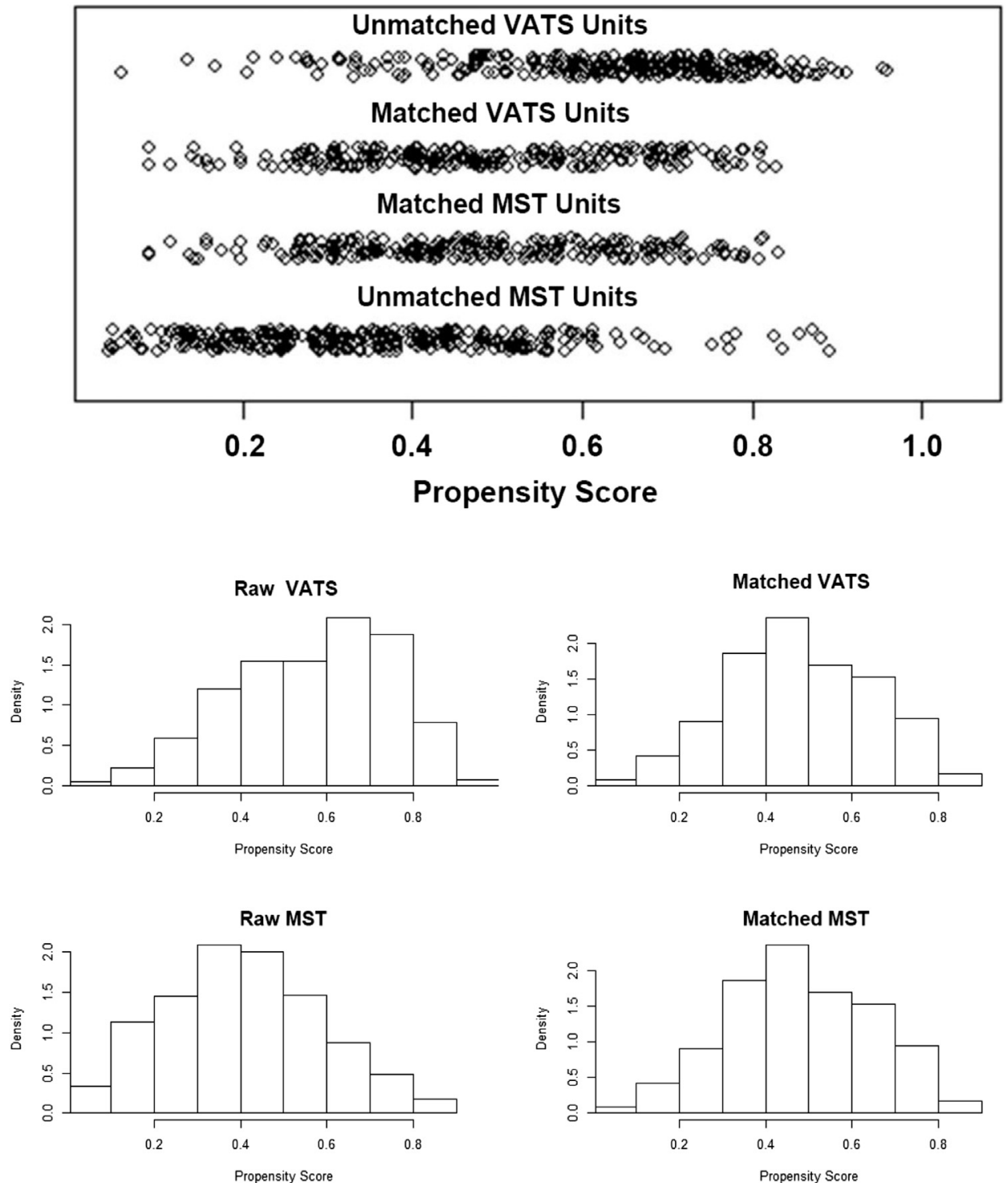

FIGURE E1. Distribution of propensity scores across 2 groups by Jitter plot and histogram. VATS, Video-assisted thoracoscopic surgery; MST, musclesparing thoracotomy. 